\title{
REVIEWS.
}

\section{TEXTBOOK OF MEDICINE.}

Edited by J. J. Conybeare. Fifth Edition. E. \& S. Livingstone, Edinburgh. I940. Price $24 \mathrm{~s}$. The popularity of this well-known text-book is shown by the necessity to publish the fifth edition in less than two years since the previous volume. This edition is a definite advance on the last as it contains several important new features. The importance of problems connected with blood transfusion has been recognised and this has been dealt with by Dr. F. A. Knott, who discusses matters such as blood grouping, stored blood, plasma infusion and blood transfusion. In the section devoted to diseases of the alimentary tract the subjects of hæmatemesis and diverticulitis have been re-written. With regard to the treatment of the latter disease, we feel that a clearer guide could be given for the management of the various manifestations of diverticulitis. In the treatment of Hirschsprung's disease, it is stated that in intractable cases lumbar sympathectomy has been performed. An important advance has been made in the treatment of these cases by recognising those which are the result of neurogenic inco-ordination using the spinal anæsthesia technique. In these cases cure will follow inferior mesenteric sympathectomy. We note that apulsion diverticulum is stated to arise at the junction of the pharynx and œsophagus whereas it is a herniation through the two parts of the inferior constriction of the pharynx. The section dealing with the respiratory tract has been revised and a new article on Congenital Cystic Disease of the Lung has been contributed.

The section dealing with the cardio-vascular system has been thoroughly revised and partially re-written, and the subject of hypertension has been brought up to date.

Attention has been given to the increasingly important therapeutic uses of the sylphonomide drug and their application in the treatment of a number of diseases, especially septicæmia, and cerebro-spinal fever.

This is a first-class text-book of medicine and is recommended to all who wish to possess an up-todate standard work on the subject.

\section{THEORY OF OGGUPATIONAL THERAPY FOR STUDENTS AND NURSES.}

By Norah A. Haworth, M.A. (Cantab.), M.R.C.S., L.R.C.P., D.P.M., and E. MARY MACDONALD, with foreword by Sir Robert Stanton Woods, M.D., F.R.C.P. Baillière, Tindall \& Cox, London. I940. Price 6s.

Especially because of the recent increased interest in and development of occupational therapy, the appearance of a book of a handy size written by two experts on the subject is very welcome. It includes chapters on occupational therapy as applied in mental disorders, tuberculosis and cardiac disease, surgical and orthopædic cases, and adequate details are given as to the organisation, staffing, equipment, etc., of an occupational therapy department. The section on mental disorders is extremely well done, but the book as a whole can be thoroughly recommended to all those interested in the subject, and every student and nurse should buy it and study it.

\section{MODERN DRUGS IN GENERAL PRACTICE.}

By Erhel Browning, M.D. Edward Arnold \& Co., London. 1940. Price Ios. 6d.

There is no doubt that Dr. Browning is a very versatile author, and in this little book she has produced a work which is excellent in every way. It consists of nine chapters and deals with the sulphonamides, gold salts, drugs acting on the heart and the autonomic nervous system, sedatives and hypnotics, diuretics and urinary antiseptics, gastro-intestinal remedies, and external applications including local anæsthetics.

For the busy practitioner who finds difficulty in keeping up to date so far as treatment goes, this little book, which only comprises 224 pages, would give him all the latest work and the latest sorts of therapy. To take the chapter on gold salts only, all the common proprietary preparations are mentioned, the difference between therapy in tuberculosis and arthritis is clearly indicated, the toxic effects are dealt with, and there is even a little paragraph on lupus erythematosus.

The opinions expressed are well balanced and give a clear indication of the type of case in which this form of therapy shows to advantage and the precautions which should be taken in its use. All the other chapters are as good as this. Perhaps the one which most interests the physician deals with the drugs which act on the autonomic nervous system.

We have to congratulate Dr. Browning most sincerely on a short book which is not only well written and to the point, but which has a very definite place in the armamentarium of every practitioner.

\section{ILLUSTRATIONS OF REGIONAL ANATOMY.}

By E. B. Jamieson. Third Edition. Sections I-V. E. \& S. Livingstone, Edinburgh. 1941. Section I price 7s. 6d. ; Section II price $15 \mathrm{~s}$.; Section III price $6 \mathrm{~s}$. ; Section IV price $4 \mathrm{~s}$. ; Section V price $4 \mathrm{~s}$.

Illustrations of regional anatomy are divided into sections and those under review comprise : Section I, Central Nervous System; Section II, Head and Neck ; Section III, Abdomen ; Section IV, Pelvis ; and Section V, Thorax. The outstanding feature of the third edition is the increase in coloured illustrations, for no less than 300 new colour-blocks have been prepared, and in over fifty of the figures there are four colours. The total number of plates in these five sections has been increased to 218 . It is certainly true that Jamieson has made an important contribution to the practical study of human anatomy, for he has succeeded in presenting to the mind pictures which are at once comprehensible and which live. The contemplation of the subject as presented in these diagrams is a real pleasure and the work is strongly recommended to all students preparing for examinations in the subject and to graduates who require to make a quick revision of their anatomical knowledge. 